\title{
Acquired bilateral superior epiblepharon with nasal extension
}

\author{
R. W. W. PATERSON, D. D. M. MaGAVIN, And J. WILliamsOn
} Ophthalmic Unit, Southern General Hospital, Glasgow

Congenital anomalies of the lids and inner canthi are not uncommon. However, supe $\overrightarrow{\dot{j}} \mathrm{\sigma}^{\circ}$ epiblepharon, an exaggerated palpebral skinfold overhanging the upper lid, is a rare congenital deformity in Caucasians, possibly transmitted as a dominant hereditäry characteristic (Duke-Elder, 1964).

The patient described in this report is of unusual interest in that the superior epildtepharon did not become noticeable until the age of I 3 years, and there was medial extenston of the skinfold over the side of the nose.

\section{Case report}

A 14-year-old British girl attended an eye outpatient clinic in October, 1967, and stated that for 6 months she had become increasingly aware of folds of skin on both upper lids, extending on कo fhe sides of her nose and giving rise to deep pits. Her parents likewise denied that these fold had existed before the age of $\mathrm{I}_{3}$ years. Furthermore, the patient had been admitted to the san oye unit at the age of 6 years for the correction of a convergent squint, and no comment was mädesat that time on the presence of any lid anomalies.

Both patient and parents were of higher than average intelligence, and it was agreed that their observations were reliable. There was no family history of eyelid abnormalities.

Examination Exaggerated palpebral skinfolds were present on both upper lids, extending from the lateral canthi across the lid, and involving the side of the nose. The lower borders of the folds 谞re in juxtaposition to the lash margins. The nasal extensions of the epiblepharon gave rise to a weilldefined pit on each side of the nose, into which a finger-tip could be inserted (Fig. I).

The patient's visual acuity with $-2 \mathrm{D}$ sph. was $6 / 6$ and $\mathrm{N}_{5}$ in each eye. Ocular and lid mơ ments were full, and convergence satisfactory. The eyes were orthophoric for distance and rivar with glasses, and both fundi were healthy.

Full medical examination excluded the presence of any other congenital anomaly; in partic dar the aetiology of a systolic murmur was investigated and found to be of no significance.

Family history The patient's parents and her three siblings were examined and found to have nor lid construction.

On the maternal side both the grandparents and all of their six children, comprising three mæ్ and three females, were said to have no lid anomalies, but were not all available for examination since some were resident abroad. There was similarly no history available of ocular abnormalifies among the six maternal cousins.

On the paternal side, both the grandparents and their three offspring, one male and two fema had no lid anomalies. There were only two cousins on this side of the family and they were stated to be normal. The patient's father had a convergent strabismus, as had the patient until surgä correction at the age of 6 years as mentioned above. 


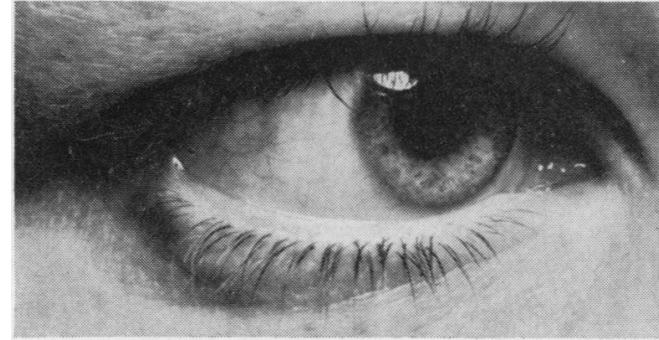

F IG. I Right eye before operation, showing epiblepharon with nasal extension, and deep pit formation at inner canthus

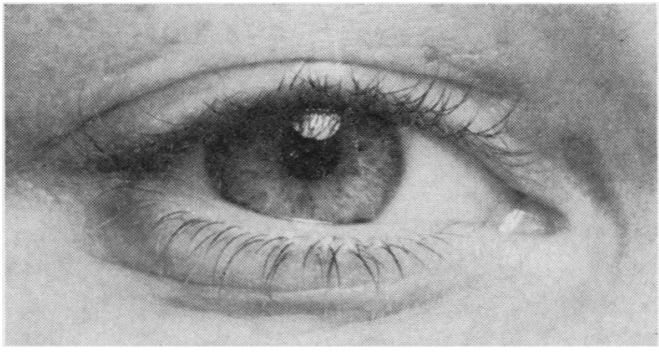

FIG. 2 Right eye 6 months after operation, illustrating removal of epiblepharon and nasal extension

Operative treatment Under general anaesthesia an elipse of skin, extending from the lateral canthus across the upper lid to the side of the nose and including the nasal fold, was excised on the left side. Skin and subcutaneous tissue were removed, and the underlying tissue was found to be healthy with no evidence of chronic inflammation or fatty infiltration. Before the operation the extent of the fold had not been marked out, and when the patient took up the prone position the epiblepharon appeared less severe than in the upright position. Thus the skin elipse removed was inadequate as far as the lid was concerned, although the nasal fold had been successfully removed. The following week the extent of the remaining epiblepharon on the left side and the epiblepharon and nasal extension on the right side were marked out with methylene blue dye when the patient was standing upright. Eliptical excisions of the skinfolds resulted in a satisfactory cosmetic appearance.

Result The patient was reviewed at the outpatient clinic 6 months later, when further improvement was observed in the cosmetic appearance as a result of scar retraction (Fig. 2). There was no interference with lid function.

\section{Summary}

A case of bilateral acquired superior epiblepharon with nasal extension is reported, and its surgical correction by eliptical excision of skin and subcutaneous tissue described. There were no other members of the patient's family with lid anomalies.

We acknowledge the help of Mr. R. Loudon Brown, of the Department of Medical Illustration, in presenting this case.

\section{Reference}

DUKE-ELDER, s. (1964) “System of Ophthalmology”, vol. 3, part 2, p. 857. Kimpton, London 